\title{
Relacionamento entre capacidade absortiva e orientação empreendedora: um estudo nos hotéis de Florianópolis (SC)
}

\author{
Relationship between absorptive capacity and entrepreneurial \\ orientation: a study of hotels of Florianópolis (SC)
}

\section{Relación entre capacidad de absorción y orientación emprendedora: un estudio en los hoteles de Florianópolis (SC)}

\section{Amanda Paterno Sbissa}

Doutoranda em Administração pela Universidade do Vale do Itajaí - UNIVALI

amandapaternosbissa@gmail.com

Carlos Ricardo Rossetto

Doutor em Engenharia de Produto pela Universidade Fecderal de Santa catarina - UFCSC

rossetto@univali.br

Carlos Eduardo Carvalho

Doutor em Administração e Turismo pela Universidade do Vale do Itajaí - UNIVALI

carlos.carvalho@unoesc.edu.br

Patrinês Aparecida Franca Zonatto

Doutoranda em Administração e Turismo pela Universidade do Vale do Itajaí - UNIVALI

patrineszonatto@gmail.com

Data de submissão: 10/07/2017 - Data de aceite: 03/04/2018

\begin{abstract}
Resumo: Este estudo teve por objetivo analisar o relacionamento entre a capacidade absortiva (ACAP) e orientação empreendedora (OE) em hotéis de Florianópolis/SC. O estudo testou a hipótese de que a Capacidade Absortiva influencia a Orientação Empreendedora. Para isso foi realizado um estudo quantitativo, de caráter descritivo, utilizando-se o método levantamento ou survey. A população alvo foi composta de hotéis situados na cidade de Florianópolis (SC). A coleta de dados foi realizada por meio de questionários com escalas tipo Likert, aplicados junto a 88 gestores dos hotéis. A análise e o teste de hipótese foram realizados por meio de modelagem de equações estruturais. Como resultado encontrado foi possível confirmar que a capacidade absortiva influencia positivamente na orientação empreendedora, sendo que no modelo testado o coeficiente de determinação encontrado foi de $52 \%$. Isto mostra que hotéis que tenham maior capacidade de absorver conhecimentos externos apresentam maior nível de práticas empreendedoras. Palavras-chave: Capacidade Absortiva; Orientação Empreendedora; Setor Hoteleiro; Florianópolis-SC.
\end{abstract}


Abstract: This study analyzes the relationship between absorptive capacity (AC) and entrepreneurial orientation (EO) in hotels in Florianópolis, Santa Catarina. The study tested the hypothesis that Absorptive Capacity influences Entrepreneurial Orientation. A quantitative study was carried out, with descriptive characteristics, using the survey method. The target population consisted of hotels located in the city of Florianópolis (SC). Data were collected through a questionnaire with Likert scales, which was applied to 88 hotel managers. Hypothesis analysis and testing was performed through the modeling of structural equations. As a result, it was possible to confirm that absorption capacity positively influences entrepreneurial orientation; in the model tested, the coefficient of determination was $52 \%$. This shows that hotels with greater capacity to absorb external knowledge present a higher level of entrepreneurial practices. Keywords: Absorptive Capacity; Entrepreneurial Orientation; Hotel sector; Florianópolis, Santa Catarina.

Resumen: Este estudio tuvo por objetivo analizar la relación entre la capacidad de absorción (CA) y la orientación emprendedora (OE) en hoteles de Florianópolis/SC. El estudio comprobó la hipótesis de que la Capacidad de Absorción influencia la Orientación Emprendedora. Para esto fue realizado un estudio cuantitativo, de carácter descriptivo, utilizando el método de levantamiento o survey. La población fue compuesta de hoteles situados en la ciudad de Florianópolis (SC). La recolección de datos fue realizada por medio de cuestionarios con escalas tipo Likert, aplicados junto a 88 gestores de hoteles. El análisis y el test de hipótesis fueron realizados por medio de modelaje de ecuaciones estructurales. Como resultado encontrado fue posible confirmar que la capacidad de absorción influencia positivamente en la orientación emprendedora, siendo que en el modelo comprobado el coeficiente de determinación encontrado fue de $52 \%$. Esto muestra que los hoteles que tengan mayor capacidad de absorber conocimientos externos presentan mayor nivel de prácticas emprendedoras. Palabras clave: Capacidad de Absorción; Orientación Emprendedora; Sector Hotelero; Florianópolis-SC.

\section{Introdução}

A hotelaria na cidade de Florianópolis é considerada como uma importante atividade econômica do turismo, determinante para o crescimento e o desenvolvimento socioeconômico, sobretudo devido à criação de emprego. A atividade do setor de serviços possui elevada dinâmica, envolvendo empreendimentos de pequeno e médio porte e relacionamentos de dependência com outros setores econômicos. Esta interação com outros segmentos gera muitas oportunidades de contato com conhecimentos externos, que se bem empregados na estratégia dos hotéis, podem gerar influências positivas no seu desempenho. Nesse sentido, a capacidade absortiva se apresenta como um processo que habilita as organizações a captar e utilizar estrategicamente estes conhecimentos externos.

A capacidade absortiva compreende como as empresas conseguem reconhecer o valor de uma determinada informação, assimilar e aplicar estes conhecimentos comercialmente (Cohen \& Levinthal, 1989; 1990; Zahra \& George, 2002).

Os conhecimentos são a base do desenvolvimento das capacidades organizacionais, sendo a capacidade absortiva das empresas elemento determinante para explicar como estas conseguem explorar novos conhecimentos, de modo a fortalecer-se, diferenciar-se competitivamente e alcançar melhor desempenho (Garzón-Castrillón, 2016).

Empresas com base de conhecimento são mais suscetíveis a oportunidades. Por outro lado, empresas que possuem orientação empreendedora e não possuem ACAP são suscetíveis de terem menos oportunidades, uma vez que possuem menor habilidade de reconhecer valor das informações (Sorescu, Chandy \& Prabhu, 2003). O interesse pelo tema capacidade absortiva é crescente e estudos apontam para a necessidade de testes empíricos sobre a temática (Flatten et al., 2011; Sciascia et al., 2014).

Engelen et al. (2014) sugerem que a capacidade absortiva fortalece o relacionamento da orientação empreendedora com o desempenho das empresas. Nesse sentido, Patel et al. (2014) argumentam que a capacidade absortiva aumenta os efeitos da orientação. Desta forma, quanto mais elevado for o nível da capacidade absortiva, mais proativas e inovadoras serão as empresas para explorar as oportunidades de negócios e mais vantagens competitivas geraram. É em função deste contexto que foi desenvolvido este trabalho, com o objetivo de analisar o relacionamento entre capacidade 
absortiva e a orientação empreendedora em hotéis de Florianópolis (SC).

Para o encadeamento adequado, este artigo foi dividido em fundamentação teórica, com foco na capacidade absortiva e orientação empreendedora; hipótese de pesquisa; metodologia de pesquisa; que discorre sobre a caracterização da pesquisa, as técnicas utilizadas para as análises e a apresentação dos resultados; e, por fim, são explanadas as considerações finais do estudo.

\section{Referencial teórico}

\section{Capacidade Absortiva}

O termo capacidade absortiva tem origem do inglês "Absorptive Capacity", sendo destaque primeiramente no trabalho seminal de Cohen \& Levinthal (1989). O conceito de capacidade absortiva apresentado nos trabalhos iniciais desenvolvidos por Cohen \& Levinthal (1989; 1990) versam sobre "a habilidade da firma identificar, assimilar e explorar o conhecimento do ambiente externo", ou ainda "a habilidade que a firma possui para avaliar, assimilar e aplicar novos conhecimentos com objetivos comerciais" (Cohen \& Levinthal, 1989, p. 569).

A capacidade absortiva teve sua discussão inicial com as investigações centradas primeiramente em estudos sobre pesquisa e desenvolvimento (P\&D). Nos artigos seminais de Cohen \& Levinthal (1989; 1990), os autores sugerem que as atividades de Pesquisa \& Desenvolvimento (P\&D) de uma empresa não apenas podem gerar novas informações, mas também aumentar de maneira significativa a capacidade da organização em assimilar e aplicar um novo conhecimento a partir de informações preexistentes.

No estudo subsequente, Cohen \& Levinthal (1990) conceituam a capacidade de absorção como um processo baseado na capacidade de absorção individual, assim o valor não estava somente nos processos de $\mathrm{P} \& \mathrm{D}$, mas relacionado aos aspectos individuais.

Posteriormente, a definição desenvolvida por Zahra \& George (2002) apresenta o conceito mais elaborado e difundido, definindo a capacidade absortiva como um conjunto de rotinas e processos organizacionais, pelos quais as organizações adquirem, assimilam, transformam e aplicam conhecimentos. De acordo com Zahra \& George (2002, p.186), a capacidade absortiva pode ser compreendida como "um grupo de rotinas e processos organizacionais pelos quais as firmas adquirem, assimilam, transformam e aplicam o conhecimento".

Zahra \& George (2002) destacam que, depois de reconhecida, a informação relevante precisa ser incorporada e transformada. Portanto, não basta ser adquirida para promover o desenvolvimento das capacidades organizacionais, sendo necessária a transformação do conhecimento externo antes de explorá-lo.

Lane, Koka \& Pathak (2006) definem a capacidade absortiva por meio de três processos: identificar e entender novo conhecimento externo potencialmente valioso por meio de aprendizado investigativo; assimilar esse novo conhecimento por meio de aprendizado transformativo e, por fim, utilizar esse conhecimento assimilado para criar novo conhecimento e resultados comerciais. Os autores sugerem ainda que a investigação da capacidade de absorção de uma determinada empresa deve ser explorada empiricamente em contextos e não apenas em atividades específicas, como P\&D.

Já o estudo de Todorova \& Durisin (2007) revisa o trabalho de Zahra \& George (2002), agregando a primeira dimensão do trabalho de Cohen \& Levinthal (1990). Os autores conceituam a capacidade absortiva como a capacidade de reconhecer o valor do novo conhecimento externo, adquiri-lo, transformá-lo e aplicá-lo. Todorova \& Durizim (2007) explicam que a capacidade de reconhecer o valor do novo conhecimento externo representa um importante componente da capacidade de absorção de uma empresa, pois a valorização não é automática, é tendenciosa e ela precisa ser promovida para permitir a absorção, o que nem sempre acontece em uma empresa. Todorova \& Durizim (2007) propõem que as empresas transformam suas estruturas de conhecimentos quando o conhecimento não pode ser assimilado. Assim sendo, a transformação representaria um processo alternativo para assimilação.

Neste sentido, Flatten et al. (2011), a partir das dimensões propostas por Zahra \& George (2002), conceituam a capacidade absortiva como sendo a habilidade da organização de adquirir, assimilar, transformar e aplicar conhecimentos externos. 
Para esses pesquisadores, as quatro dimensões de Zahra \& George (2002) capacitam as organizações a explorarem novas conhecimentos e, dessa forma, aumentam a performance, caracterizando a capacidade absortiva como uma fonte de vantagem competitiva. Para esta pesquisa, optou-se por mensurar a capacidade absortiva, seguindo as dimensões propostas por Zahra \& George (2002), que dividem a capacidade absortiva em quatro dimensões: aquisição e assimilação formam a capacidade absortiva potencial (PACAP), e Transformação e Aplicação formam a capacidade absortiva realizada (RACAP).

Outras pesquisas estão sendo realizadas para maior entendimento a respeito do tema capacidade absortiva. Dentre elas, uma pesquisa quantitativa com empresas de manufatura indígenas em operações na Nigéria em um período de seis anos. A pesquisa concluiu que os investimentos em atividades de P\&D e inovação são os principais fatores de capacidades inovadoras nas empresas (DUTSE, 2013). Outro estudo a respeito do tema buscou examinar capacidade de absorção e desempenho. A pesquisa teve como objetivo examinar os antecedentes do potencial dos indivíduos (aquisição e assimilação) e (transformação e aplicação), incluindo os benefícios previstos para compartilhar conhecimentos (TIAN; SOO, 2014). Outra pesquisa teve como objetivo identificar e categorizar o conhecimento das práticas de gestão das PME e como podem adaptá-las para desenvolver a capacidade de absorção. A pesquisa realizada em pequenas empresas portuguesas concluiu que essas pequenas empresas estão envolvidas na gestão do conhecimento, prática por meio de colaboração com parceiros de negócios, favorecendo processos de aprendizagem baseados na experiência, transferência de conhecimento para funcionários e absorção de conhecimento (VALENTIM; LISBOA; FRANCO, 2015). Em complemento, Garzón-Castrillón (2016) aborda que as capacidades organizacionais são construídas com base no conhecimento das empresas, de forma que a capacidade absortiva fortalece o desempenho e contribui para a exploração de novos conhecimentos.

\section{Orientação Empreendedora}

O termo orientação empreendedora (OE) é definido por Miller (1983) como sendo a atividade de uma empresa de se sujeitar a riscos.
O autor afirma que empresas que possuem $\mathrm{OE}$ são pioneiras em inovações, proativas em atitudes de ataque ao mercado e possuem alta capacidade de assumir riscos. Em contrapartida, o autor argumenta que empresas que não possuem $\mathrm{OE}$ são aquelas mais conservadoras que inovam pouco e são cautelosas com relação às mudanças.

A orientação empreendedora foi conceituada por Covin \& Slevin (1989) como uma atitude empresarial empreendedora determinada por constantes inovações em produtos e tecnologia, alta competição e elevada aceitação em assumir riscos. Em complemento, Lumpkin \& Dess (1996) argumentam que a $\mathrm{OE}$ corresponde às práticas de estratégias na condução dos negócios por meio de processos, ações e atividade de tomada de decisão, com o intuito de criar novas oportunidades (Lumpkin \& Dess, 1996).

Covin, Green \& Slevin (2006) conceituaram a OE como sendo um construto estratégico relacionado às preferências e aos comportamentos gerenciais dentro da organização. Assim, a orientação empreendedora se constitui como um importante tema na identificação do perfil empreendedor da empresa e suas influências nas estratégias organizacionais e no desempenho (Rauch et al., 2009).

Para efeitos desse estudo, foram adotadas as dimensões propostas por Lumpkin \& Dess (1996) sendo elas inovatividade, capacidade de assumir riscos, proatividade, autonomia e agressividade competitiva.

A inovatividade é a tendência da empresa em incentivar novas ideias, experimentos, processos criativos, que possam ocasionar produtos ou serviços novos (Lumpkin \& Dess, 1996). Já a capacidade de assumir riscos é uma dimensão da OE que se refere ao grau de risco correspondente das várias decisões de destinações dos recursos, bem como na escolha de produtos e mercados, refletindo, de certa forma, um critério para decisões e um padrão de tomada de decisão (Venkatraman, 1989). Diz respeito a como uma empresa está disposta a arriscar por meio de investimentos a fim de obter os resultados esperados (Lumpkin \& Dess, 1996).

A dimensão proatividade refere-se ao quanto uma organização busca ser líder, descobrindo e explorando novas oportunidades, identificando e antecipando tendências. A proatividade pode ser 
manifestada pela busca de novas oportunidades, as quais podem ou não ser relacionadas à atual linha de operação da organização, introdução de novos produtos (Venkatraman, 1989). As empresas que são tidas como proativas acompanham tendências, identificam futuras necessidades dos clientes, não apenas seguindo o mercado, mas se antecipando às mudanças do ambiente em que estão inseridas (Lumpkin \& Dess, 1996). Já a autonomia corresponde ao nível de liberdade de uma empresa, ou seja, como ela encoraja a independência dos funcionários pela ação e organização do trabalho, estimulando iniciativas empreendedoras (Lumpkin \& Dess, 1996). Já a última dimensão de $\mathrm{OE}$ é a Agressividade Competitiva, que corresponde à capacidade de uma empresa atuar em mercados de maneira altamente competitiva com baixos preços e copiando práticas e técnicas de competidores de sucesso (Lumpkin \& Dess, 1996).

O interesse pelo tema orientação empreendedora está em crescimento e ainda merece atenção dos pesquisadores da área. $\mathrm{O}$ estudo de Sciascia et al. (2014) procurou analisar como a capacidade de absorção pode atuar como um fator chave que determina a efetividade da orientação empreendedora em indústrias de baixa e média tecnologia. Os resultados evidenciam que empresas de médio porte com sede na Itália confirmam a hipótese de que, nas indústrias de baixa e média tecnologia, a orientação empreendedora tem um efeito positivo no desempenho da empresa, quando associada a altos níveis de capacidade Potencial e Capacidade de Absorção Realizada.

Estudos recentes têm sido realizados a respeito do tema orientação empreendedora e sua relação com outras temáticas na área de estratégia nas organizações no contexto nacional. Tonial (2014) abordou a orientação empreendedora em vinícolas internacionalizadas no Sul do Brasil, buscando identificar e apresentar elementos que caracterizam as dimensões da $\mathrm{OE}$ do setor pesquisado. Os achados da pesquisa confirmaram a relação entre orientação empreendedora, empreendedorismo internacional e internacionalização. Martens et al. (2015) validaram um modelo de mensuração da orientação empreendedora, e no estudo os resultados revelaram que existe uma relação positiva entre orientação empreendedora e maturidade em gerenciamento de projetos, abordando que a inovação, a assunção de riscos e a proatividade exercem um impacto positivo sobre a maturidade de gerenciamento de projetos. Outro estudo recente buscou analisar a relação existente entre capacidade absortiva e orientação empreendedora em agências bancárias. Avançando o conhecimento sobre orientação empreendedora, a pesquisa confirmou que o construto orientação empreendedora é multidimensional, tendo sido composto por duas dimensões distintas, uma relacionada à inovatividade e proatividade, e outra relacionada à aceitação de risco (ROSSETTO et al.; 2016).

\section{Hipótese de Pesquisa}

A partir da revisão dos principais autores que abordam os temas de Capacidade Absortiva e Orientação Empreendedora, foi elaborada a hipótese de pesquisa. Estudos mostram a relação positiva entre essas duas temáticas, abordando que uma fase fundamental da capacidade absortiva se constitui em avaliar as oportunidades e interpretar as novas informações, para que assim possam ser incorporadas pelas empresas. Portanto, empresas com base de conhecimento são mais suscetíveis a oportunidades. Por outro lado, empresas que possuem orientação empreendedora e não possuem capacidade absortiva são suscetíveis de terem menos oportunidades, uma vez que possuem menor habilidade de reconhecer valor das informações valiosas (Sorescu, Chandy \& Prabhu, 2003).

Zahra, Filatotchev \& Wright (2009) argumentam que a capacidade absortiva é determinante na orientação empreendedora, uma vez que aperfeiçoa a habilidade de reconhecer e aproveitar novas oportunidades. No mesmo sentido, Sciascia et al. (2014) afirmam que a capacidade de absorção pode agir como um fator chave na determinação da eficácia da orientação empreendedora. Assim, chega-se à seguinte Hipótese: Quanto maior a capacidade absortiva do hotel, maior será sua orientação empreendedora.

\section{Método}

Este estudo caracteriza-se como uma pesquisa quantitativa, de caráter descritivo, utilizando-se o método survey. As pesquisas quantitativas são adequadas quando se desejam analisar e mensurar a relação entre variáveis.

A população definida para a realização da pesquisa compreende os hotéis localizados na cidade de Florianópolis (Santa Catarina). Dessa 
forma, buscou-se a aplicação do questionário em todos os hotéis da capital catarinense.

A coleta de dados realizou-se no período de 08 de setembro a 05 de outubro de 2016, com questionários aplicados pessoalmente pelos pesquisadores junto aos gestores dos hotéis. Como os órgãos relacionados à hotelaria de Florianópolis não passaram as informações com relação ao número total de hotéis, primeiramente foi efetuada a coleta com os hotéis vinculados à Associação Brasileira da Indústria Hoteleira Santa Catarina (ABIH-SC), sendo alcançado a totalidade dos hotéis situados em Florianópolis pertencentes à ABIH-SC. Após, foi expandida a pesquisa também para os hotéis associados ao Sindicato de Hotéis, Restaurantes, Bares e Similares de Florianópolis (SHRBS), divididos em hotéis Centro, Continente, Praias do Leste, Praias do Sul e Praias do Norte, tendo sido obtido um total de 88 questionários validados.

O instrumento de coleta de dados foi constituído por escalas do tipo Likert de sete pontos, as quais mensuraram a capacidade absortiva dos hotéis pesquisados, segundo as dimensões propostas por Zahra \& George (2002), baseadas no trabalho desenvolvido por Tenconi (2015), composto de 20 afirmativas.
Para mensurar a Orientação Empreendedora, foi utilizada escala desenvolvida por Martens et al. (2015) e adaptada para o setor hoteleiro, composto por 20 afirmativas divididas entre as dimensões de Inovatividade, Assumir Riscos, Proatividade, Autonomia e Agressividade Competitiva, propostas por Lumpkin \& Dess (1996).

$\mathrm{O}$ instrumento usado na coleta passou por um processo de validação textual feito por especialistas acadêmicos, e por um pré-teste realizado com quatro gestores de hotéis não pertencentes à população do estudo nas cidades de São José (SC), Blumenau (SC) e Bombinhas (SC). Os quatro blocos utilizados na pesquisa com a descrição das variáveis e indicadores podem ser visualizados no Quadro 1.

\section{Técnicas de Análise}

A validação das escalas para uso no setor hoteleiro foi realizada com o auxílio de análise fatorial. Para tanto, adotaram-se os critérios apresentados no Quadro 2, para verificação da validade e da adequação dos constructos de capacidade absortiva e orientação empreendedora a partir da Análise Fatorial Exploratória (AFE). Após a validação dos construtos, procedeu-se

Quadro 1: Descrição das Variáveis e dos Indicadores

\begin{tabular}{|c|c|c|c|}
\hline Blocos & Dimensões & Indicadores & Fonte \\
\hline $1^{\mathrm{o}}$ & $\begin{array}{l}\text { Capacidade } \\
\text { Absortiva }\end{array}$ & $\begin{array}{c}\text { - Aquisição } \\
\text { - Assimilação } \\
\text { - Transformação } \\
\text { - Aplicação do conhecimento }\end{array}$ & $\begin{array}{c}\text { Zahra \& George } \\
(2002) ; \\
\text { Tenconi }(2015) .\end{array}$ \\
\hline $2^{\mathrm{o}}$ & $\begin{array}{l}\text { Orientação } \\
\text { Empreendedora }\end{array}$ & $\begin{array}{l}\text { - Inovatividade } \\
\text { - Capacidade de assumir riscos } \\
\text { - Proatividade } \\
\text { - Autonomia } \\
\text { - Agressividade competitiva }\end{array}$ & $\begin{array}{l}\text { Lumpkin \& Dess } \\
\text { (1996); } \\
\text { Martens et al., } \\
\text { (2015). }\end{array}$ \\
\hline $3^{\circ}$ & $\begin{array}{c}\text { Desempenho em } \\
\text { Hotéis }\end{array}$ & $\begin{array}{c}\text { - Vendas Totais } \\
\text { - Taxa de Ocupação } \\
\text { - Margem de lucro sobre as vendas } \\
\text { totais } \\
\text { - Diária média } \\
\text { - Custo médio por diária vendida }\end{array}$ & $\begin{array}{l}\text { Carvalho, Rossetto } \\
\text { \& Verdinelli (2016) }\end{array}$ \\
\hline $4^{\circ}$ & $\begin{array}{c}\text { Características dos } \\
\text { hotéis }\end{array}$ & $\begin{array}{c}\text { - Tamanho do hotel, medido (UH) } \\
\text { - Classificação do hotel } \\
\text { - Propriedade e Gestão do hotel } \\
\text { - Segmento de Atuação }\end{array}$ & $\begin{array}{l}\text { Elaborado para a } \\
\text { pesquisa }\end{array}$ \\
\hline
\end{tabular}

Fonte: Elaborado pelos autores (2016). 
à análise do relacionamento entre eles, sendo utilizada a Modelagem de Equações Estruturais por meio da técnica dos Mínimos Quadrados Parciais com a utilização do software Smart PLS. O Quadro 2 apresenta uma síntese dos critérios a serem utilizados para se avaliar a adequação dos constructos de mensuração a partir das análises fatoriais realizadas.

\section{Análise dos Resultados}

A amostra contou com 88 hotéis, dos quais 53 (60\%) estão localizados na praia, e 55 (62\%) estão classificados na categoria turístico ou três estrelas, sendo que 67 (76\%) possuem gestão independente; enquanto os demais 21 hotéis pertencem a redes hoteleiras. Quanto aos respondentes, 55 (62\%) são do sexo masculino.

Foi realizada análise fatorial com rotação Varimax para validar os indicadores e identificar as dimensões ou os fatores que compõem a capacidade absortiva e a orientação empreendedora.

A Análise Fatorial dos indicadores de Capacidade Absortiva gerou três fatores. Observou-se que os indicadores relacionados à assimilação e à aplicação apresentaram cargas significativas no mesmo fator. Zahra \& George (2002) propuseram a existência de quatro dimensões: aquisição, assimilação, transformação

Quadro 2: Critérios sugeridos para avaliar a adequação dos constructos

\begin{tabular}{|l|c|}
\hline $\begin{array}{l}\text { Critérios para validação dos } \\
\text { constructos }\end{array}$ & Valor Esperado \\
\hline Alfa de Cronbach & $>0,70$ \\
\hline Comunalidades & $>0,500$ \\
\hline Kaiser-Meyer-Olkin (KMO) & $>0,70$ \\
\hline $\begin{array}{l}\text { Teste de Esfericidade de } \\
\text { Bartlett }\end{array}$ & $\mathrm{p}<0,05$ \\
\hline Carga no Fator & $>0,50$ \\
\hline Carga nos outros construtos & $<0,50$ \\
\hline Correlação inter-itens mínima a & $>0,300$ \\
\hline $\begin{array}{l}\text { Critério de definição do } \\
\text { número de componentes } \\
\text { considerado }\end{array}$ & Carga $>1,00$ \\
\hline
\end{tabular}

Fonte: Adaptado de Hair et al. (2009). e aplicação. Nessa pesquisa, os indicadores que deveriam mensurar a assimilação apresentaram cargas no mesmo fator dos indicadores que mensuram a aplicação de conhecimento. Considerando que as cargas de assimilação são mais baixas que as de aplicação e considerando ainda que teoricamente a capacidade absortiva só se completa com a aplicação do conhecimento adquirido, optou-se pela exclusão da assimilação, utilizando-se o construto capacidade absortiva, composto por três dimensões, aquisição, transformação e aplicação.

Alguns estudos empíricos têm buscado testar essas dimensões e encontram resultados divergentes. Lane et al. (2006) propõem que a capacidade absortiva seja formada por três dimensões, reconhecimento, assimilação e aplicação. Todorova \& Durisin (2007) entendem que as dimensões de assimilação e transformação propostas por Zahra\& George nãonecessariamente acontecem separadamente.

Assim, apesar de Zahra \& George (2002) proporem quatro dimensões, diversos trabalhos têm tido resultados divergentes quanto às dimensões. Um estudo sobre capacidade absortiva, realizado na indústria têxtil de Santa Catarina, apresentou indicadores relacionados à aquisição e à assimilação no mesmo fator (Manthey, 2016). A análise fatorial de Tenconi (2015) também obteve resultado semelhante, sendo configuradas as dimensões de aquisição, transformação e aplicação.

No setor hoteleiro estudado, é possível que os processos de assimilação de conhecimento estejam misturados aos outros processos. Observando a amostra, caracterizada majoritariamente por hotéis independentes, com gestão possivelmente familiar, é possível entender que o processo de assimilação não seja destacado, mas sejam mais fortemente presentes os processos de aquisição e a direta aplicação do conhecimento.

Concluída a análise fatorial, procedeu-se à análise de confiabilidade das três dimensões encontradas. Todas as três dimensões apresentaram valores de Alfa de Cronbach acima de 0,800, correlação item-total acima de 0,500 , e correlação entre itens acima de 0,300 , demonstrando que as escalas são confiáveis. O Quadro 3 apresenta as dimensões validadas e seus indicadores.

Com relação ao construto Orientação Empreendedora, foi realizada a análise fatorial 
Quadro 3: Dimensões da Capacidade Absortiva e seus indicadores

\begin{tabular}{|c|c|}
\hline Dimensão & Indicadores \\
\hline Aquisição & $\begin{array}{l}\text { CA_01-A busca de informações relevantes sobre o setor hoteleiro é tarefa } \\
\text { cotidiana em nosso hotel. } \\
\text { CA_02-Nosso hotel motiva os funcionários a usarem fontes de informação } \\
\text { dentro do nosso setor de atuação. } \\
\text { CA_04-Nosso hotel valoriza e busca informações além do nosso setor de } \\
\text { atuação. } \\
\text { CA_05- Nosso hotel é orientado para monitorar continuamente tendências e } \\
\text { para descobrir oportunidades a serem exploradas. }\end{array}$ \\
\hline Transformação & $\begin{array}{c}\text { CA_09-Realizamos encontros periódicos entre áreas/departamentos para a troca } \\
\text { de ideias, problemas, novos desenvolvimentos e realizações. } \\
\text { CA_11- Nossos funcionários têm a capacidade de estruturar e utilizar os } \\
\text { conhecimentos que adquirem. } \\
\text { CA_12- Ligar o conhecimento existente com novas ideias é atividade realizada } \\
\text { com sucesso por nossos funcionários. } \\
\text { CA_13- Os funcionários do nosso hotel são capazes de aplicar novos } \\
\text { conhecimentos em seu trabalho prático. } \\
\text { CA_14- Nosso hotel entende rapidamente novas oportunidades para servir } \\
\text { nossos clientes a partir das tecnologias existentes. } \\
\text { CA_17 - Nosso hotel tem a capacidade de trabalhar de forma mais eficaz através } \\
\text { do emprego de novas tecnologias. }\end{array}$ \\
\hline Aplicação & $\begin{array}{c}\text { CA_15 Nosso hotel rapidamente reconhece a utilidade de novos conhecimentos } \\
\text { com os conhecimentos já existentes. } \\
\text { CA_18 Nosso hotel tem capacidade de usar e explorar novos conhecimentos para } \\
\text { responder rapidamente às mudanças de mercado. } \\
\text { CA_19 Nosso hotel tem capacidade de revisar os procedimentos de negócios } \\
\text { com base em novos conhecimentos adquiridos. } \\
\text { CA_20 Nosso hotel é capaz de desenvolver serviços com base em novos } \\
\text { conhecimentos adquiridos. }\end{array}$ \\
\hline
\end{tabular}

com rotação Oblimin com normalização de Kaiser. As comunalidades apresentaram resultados superiores a 0,40 em concordância com o estabelecido por Hair et al. (2009), que sugerem como regra geral que apenas indicadores com comunalidades acima de 0,40 sejam mantidos.

Foram retirados alguns indicadores que apresentaram problemas de baixa comunalidade, e de cargas cruzadas, o que indica que estes indicadores são eram boas medidas do construto Orientação Empreendedora. Dos 20 indicadores originais, 5 indicadores foram excluídos durante as etapas da análise fatorial.

O resultado final da análise fatorial exploratória demonstra que os indicadores de Orientação Empreendedora apresentaram cargas acima de 0,500 , tendo como menor componente o valor de 0520 . Os fatores criados explicam $67,21 \%$ da variância dos dados. A medida de adequação da amostra de KMO foi calculada em 0,863 , e o teste de esfericidade de Bartlet, com significância de 0,000 , demonstrou que a análise fatorial é válida. Diferente do que propõem Lumpkin \& Dess (1996), os resultados da análise fatorial apresentaram quatro dimensões: proatividade, risco, autonomia e inovatividade.

Os indicadores previstos para a dimensão Agressividade Competitiva apresentaram cargas na dimensão proatividade, indicando que possivelmente os indicadores DC_01 (Em nosso hotel monitoramos e reagimos rapidamente às ações da concorrência) e DC_03 (Em nosso hotel usamos intensivamente propaganda e promoções para conquistar clientes) podem estar, nesse setor, mais relacionados com a proatividade do que com a agressividade competitiva.

Apesar de Lumpkin \& Dess (1996) argumentarem sobre a existência das cinco dimensões, estudos empíricos têm apresentado 
resultados diferentes. No estudo desenvolvido por Carvalho \& Rossetto (2015) se encontram duas dimensões de OE, sendo a primeira a aceitação de risco e a outra relacionada a dois componentes: inovatividade e proatividade.

Realizada a análise fatorial, prosseguiuse à análise de confiabilidade das quatro dimensões encontradas. A primeira dimensão com indicadores chamados de proatividade foi originada de três dimensões teóricas, sendo composta por três indicadores de proatividade DP_01, DP_03 e DP_04, um indicador de autonomia DA_04 (Existem práticas estabelecidas para o desenvolvimento do comportamento empreendedor em nosso hotel) e dois de agressividade competitiva DC_01 (Em nosso hotel monitoramos e reagimos rapidamente às ações da concorrência) e DC_03 (Em nosso hotel usamos intensivamente propaganda e promoções para conquistar clientes). Essa dimensão apresentou Alfa de Cronbach de 0,867, correlação entre itens mínima de 0,377 e máxima de 0,625, e correlação item-total mínima de 0,591 e máxima de 0,719.

A dimensão com os indicadores capacidade de assumir risco apresentou Alfa de Cronbach de 0,849 , correlação entre itens mínima de 0,615 e máxima de 0,721 , e correlação item-total mínima de 0,665 e máxima de 0,746. A dimensão com indicadores de autonomia apresentou Alfa de Cronbach de 0,740, correlação entre itens mínima de 0,589 e máxima de 0,589 , e correlação item-total mínima de 0,589 e máxima de 0,589; enquanto a dimensão com os indicadores de inovatividade apresentou Alfa de Cronbach de 0,718, correlação entre itens mínima de 0,340 e máxima de 0,489 , e correlação item-total mínima 0,482 e máxima de 0,580 .

O Quadro 4 apresenta as dimensões da orientação empreendedora e seus indicadores validados.

Quadro 4: Dimensões da Orientação Empreendedora e seus indicadores

\begin{tabular}{|c|c|}
\hline Dimensão & Indicadores \\
\hline Risco & $\begin{array}{l}\text { DR_01-A administração do nosso hotel tem propensão a aprovar projetos de alto } \\
\text { risco (com chances de retornos muito altos). } \\
\text { DR_02- Atitudes arriscadas são necessárias para alcançar os objetivos em nosso } \\
\text { hotel. } \\
\text { DR_04-Quando diante de situações de tomada de decisão que envolve incerteza, } \\
\text { a organização adota uma postura audaciosa e agressiva com o objetivo de } \\
\text { maximizar a probabilidade de explorar oportunidades em potencial. }\end{array}$ \\
\hline Proatividade & $\begin{array}{c}\text { DA_04- Existem práticas estabelecidas para o desenvolvimento do } \\
\text { comportamento empreendedor em nosso hotel. } \\
\text { DC_01- Em nosso hotel monitoramos e reagimos rapidamente às ações da } \\
\text { concorrência } \\
\text { DC_03-Em nosso hotel usamos intensivamente propaganda e promoções para } \\
\text { conquistar clientes } \\
\text { DP_01- Nosso hotel adota ações no mercado às quais os competidores } \\
\text { respondem. } \\
\text { DP_03-O monitoramento do ambiente é prática constante em nosso hotel } \\
\text { (clientes, concorrentes, busca de oportunidades, etc.) } \\
\text { DP_04-A administração tende a estar à frente de outros competidores na } \\
\text { introdução de novos serviços e produtos. }\end{array}$ \\
\hline Inovatividade & $\begin{array}{c}\text { DA_03- Os empregados desempenham um papel importante na identificação e } \\
\text { seleção de oportunidades empresariais que a organização persegue. } \\
\text { DI_01- A gestão nosso hotel inova muito em processos dando preferência a } \\
\text { projetar seus próprios métodos de atuação. } \\
\text { DI_03- Nosso hotel utiliza fontes externas de recursos financeiros para inovação. }\end{array}$ \\
\hline Autonomia & $\begin{array}{c}\text { DA_01- Em nosso hotel esforços de indivíduos e/ou equipes que trabalham de } \\
\text { forma autônoma são incentivados. } \\
\text { DA_02- Em nosso hotel os funcionários perseguem oportunidades de } \\
\text { negócio, tomam decisões por conta própria, sem referência constante de seus } \\
\text { supervisores. }\end{array}$ \\
\hline
\end{tabular}


A análise da relação entre capacidade absortiva e orientação empreendedora foi realizada através de modelagem de equações estruturais. Utilizandose a técnica dos Mínimos Quadrados Parciais - PLS e iniciando-se com a análise do modelo de mensuração, procederam-se aos testes de confiabilidade composta (C.R.), Variância Média Extraída (AVE) e Alfa de Cronbach. A análise estrutural deu-se pela avaliação do coeficiente de determinação $\left(\mathrm{R}^{2}\right)$ e da significância do caminho entre ACAP e OE medida pelo teste t. A Tabela 1 mostra os índices de confiabilidade do modelo de mensuração.

Os valores obtidos são aceitáveis, uma vez que todos apresentam Alfa de Cronbach e confiabilidade composta acima de 0,70, e que apenas um construto apresenta valor de Análise da Variância Extraída (AVE) inferior a 0,50.

Observou-se que a capacidade absortiva gera efeito significativo sobre a orientação empreendedora, ou seja, $52 \%$ da variação da orientação empreendedora é determinado pela influência da capacidade absortiva. A Figura 1 apresenta o modelo de relacionamentos testado.

Realizado o teste $\mathrm{t}$ através da rotina de bootstrapping do PLS, tendo sido rodada com 1000 sub-amostras, o valor gerado nessa relação é 10,153, sendo superior ao valor esperado de $\mathrm{t}>$
1,96, o que demonstra que o efeito da capacidade absortiva sobre a orientação empreendedora no segmento hoteleiro de Florianópolis é estatisticamente significativo.

Assim, a hipótese de que quanto maior a capacidade absortiva de um hotel maior será sua orientação empreendedora foi suportada. Em um mercado com concorrência crescente, em que cada vez mais as grandes redes hoteleiras, profissionalizadas e dotadas de inteligência de mercado obtêm vantagem competitiva, é essencial aos hotéis, especialmente aos hotéis de gestão independente, característica marcante da amostra deste estudo, que dediquem tempo e energia aos seus processos de absorção de conhecimento do mercado, pois este conhecimento absorvido gera ações mais empreendedoras.

\section{Considerações finais}

O objetivo desta pesquisa foi analisar a relação entre capacidade absortiva e orientação empreendedora em hotéis localizados na cidade de Florianópolis (SC). Com base no referencial teórico, foi elaborada a hipótese de pesquisa. Desta forma, os resultados confirmam uma relação positiva entre capacidade absortiva e orientação empreendedora.

Com base disso, entende-se a utilização de práticas de absorver conhecimento, adotada

Tabela 1: Indicadores do modelo testado.

\begin{tabular}{|l|c|c|c|c|}
\hline & A.V.E & $\begin{array}{c}\text { Confiabilidade } \\
\text { composta }\end{array}$ & $\mathrm{R}^{2}$ & Alfa de Cronbach \\
\hline Aplicação & 0,87 & 0,94 & 0,73 & 0,91 \\
\hline Aquisição & 0,70 & 0,90 & 0,76 & 0,86 \\
\hline Transformação & 0,60 & 0,90 & 0,80 & 0,86 \\
\hline $\begin{array}{l}\text { Capacidade } \\
\text { Absortiva }\end{array}$ & 0,52 & 0,93 & & 0,92 \\
\hline Autonomia & 0,80 & 0,89 & 0,44 & 0,74 \\
\hline Inovatividade & 0,56 & 0,83 & 0,71 & 0,73 \\
\hline Proatividade & 0,61 & 0,91 & 0,80 & 0,87 \\
\hline Risco & 0,64 & 0,88 & 0,50 & 0,81 \\
\hline $\begin{array}{l}\text { Orientação } \\
\text { Empreendedora }\end{array}$ & 0,40 & 0,92 & 0,52 & 0,90 \\
\hline
\end{tabular}

Fonte: Dados da pesquisa (2017). 


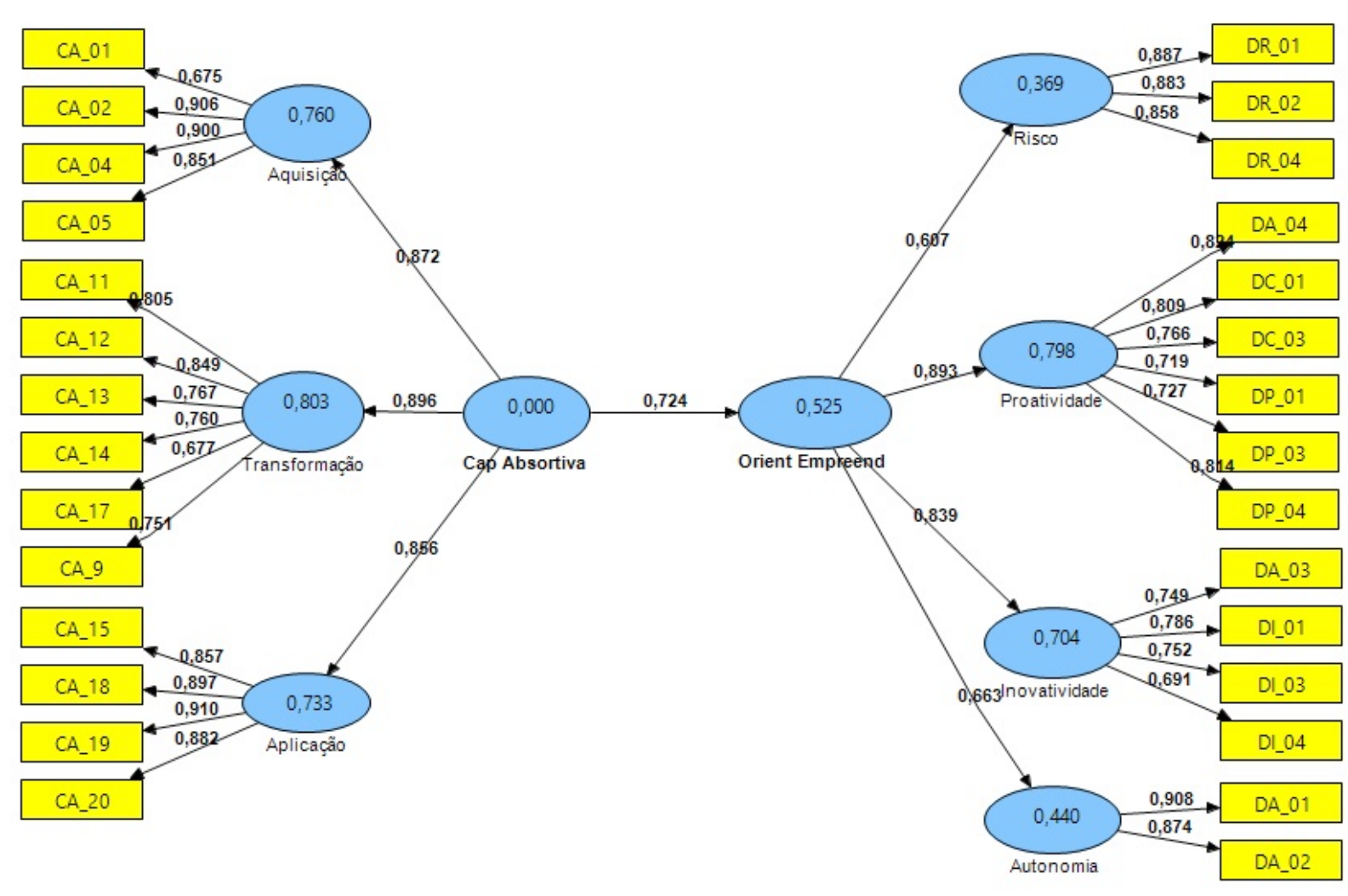

Figura 1: Modelo estrutural de relacionamento entre ACAP e OE Fonte: Dados da pesquisa (2017).

pelos hotéis analisados, influencia na orientação empreendedora. Isto porque $52 \%$ da variação da orientação empreendedora é determinada pela influência da capacidade absortiva. Para os hotéis da amostra, quanto mais conhecimento adquirido, transformado e aplicado empiricamente, maior resulta em sua orientação empreendedora. Assim, é fundamental que os gestores dos hotéis estejam atentos aos conhecimentos que estão fora da sua unidade de hospedagem, sejam aqueles conhecimentos oriundos dos fornecedores e parceiros, sejam aqueles oriundos dos próprios concorrentes, assim como aqueles dos próprios clientes e órgãos de apoio e regulamentação da atividade. Criar mecanismos para interiorizar estes conhecimentos favorece a adoção de ações mais empreendedoras.

Um detalhe importante a ser repensado é a questão da assimilação de conhecimentos. Seria interessante avaliar, em unidades hoteleiras relativamente pequenas e caracterizadas pela gestão independente, até que ponto é necessário assimilar o conhecimento antes de aplicá-lo no mercado. Aparentemente, os hotéis da amostra adotam uma postura mais direta no sentido de aplicação direta do conhecimento, sem a necessidade de muita interpretação e assimilação por parte da sua equipe. Se por um lado isto demonstra certa agilidade na ação, por outro lado, pode demonstrar uma falta de padronização no conhecimento adquirido, bem como nos novos processos oriundos deste conhecimento.

Uma limitação do estudo é que os dados achados não podem ser generalizados, uma vez que correspondem a um segmento específico que é o setor hoteleiro da cidade de Florianópolis. Quantoàs recomendações para novos estudos, cabe apontar que seria interessante que se procurasse verificar como se dão os relacionamentos entre as variáveis aqui estudadas em hotéis de outras cidades, além de outros segmentos econômicos, a fim de verificar se os resultados se apresentam de maneira equivalente.

\section{Referências}

Carvalho, C. E., \& Rossetto, C. R. (2015). Capacidades Organizacionais e seu Efeito na Orientação Empreendedora: um estudo através da Modelagem de Equações Estruturais. Belo Horizonte: XXXIX Encontro da Anpad.

Cohen, W., \& Levinthal. D. (1989). Innovation and Learning: The Two Faces of R\&D. The Economic Journal, v. 99, n. 397, p. 569-596.

Cohen, W., \& Levinthal. D. (1990). Absorptive 
Capacity: A New Perspective on Learning and Innovation. Administrative Science Quarterly, v.35, n. 1, p. $128-152$.

Covin, J. G., \& Slevin, D. P. (1989). Strategic management of small firms in hostile and benign environments. Strategic Management Journal, v. 10, n. 1, p. 75-87.

Covin, J. G., Green, K. M., \& Slevin, D. P. (2006). Strategic process effects on the entrepreneurial orientation-sales growth rate relationship. Entrepreneurship theory and practice, v. 30, n. 1, p. 57-81.

Engelen, A. Kube, H., Schmidt, S., \& Flatten, T. C. (2014). Entrepreneurial orientation in turbulent environments: The moderating role of absorptive capacity. Research Policy, v. 43, n. 8, p. 1353-1369.

Flatten, T. C., Engelen, A., Zahra, S. A \& Brettel, M. A. (2011). measure of absorptive capacity: Scale development and validation. European Management Journal, v. 29, n. 2, p. 98-116.

Flatten, T., Greve, I. \& Brettel, M. (2011). Absorptive Capacity and Firm Performance in SME's: The Mediating Influence of Strategic Alliances. European Management Review, v. 8, n. 3, p. 137-152.

Garzón-Castrillón, M. A. (2016). Capacidad dinámica de absorción. Estudio de caso. Orinoquia, v. 20, n. 1, p. 97-118.

Hair, Jr, J.F., Black, W. C., Babin, B. J., Anderson, R. E. \& Tathan, R. L. (2009). Análise Multivariada de dados. 5. ed., Porto Alegre: Bookman, 2009.

Lane, P.J., Koka, B. \& Pathak, S. (2006). The Reification of Absorptive Capacity; A Critical Review and Rejuvenation of the Construct. Academy of Management Review, v. 31, n. 4, p. 833-863.

Lumpkin, G. T. \& Dess, G. G. (1996). Clarifying the entrepreneurial orientation construct and linking it to performance. Academy of management Review, v. 21, n. 1, p. 135-172.

Manthey, N.B. (2016). O Impacto das Capacidades de Absorção e de Inovação no Desempenho da Inovação de Produto. Dissertação (Mestrado) - Curso de Administração, Universidade do Vale do Itajaí, Biguaçu.

Dai Prá Martens, C., Doro, A. C., K., Martens, M. L. \& Da Silva, D. (2015). Relação entre Orientação Empreendedora e Maturidade na Gestão de Projetos em Empresas Brasileiras de Software. Revista IberoAmericana de Estratégia (RIAE), v. 14, n. 3.

Dutse, A. Y. (2013). Linking absorptive capacity with innovative capabilities: A survey of manufacturing firms in Nigeria. 2. ed. [s. L.]: International Journal OfTechnology Management \& Sustainable Development, 183 p. 12 v.

Miller, D. (1983). The correlates of entrepreneurship in three types of firms. Management science, v. 29, n. 7, p. 770-791.

Patel, P. C., Kohtamäki, M., Parida, V. \& Wincent, J. (2015). Entrepreneurial orientation $\square$ as $\square$ experimentation and firm performance: The enabling role of absorptive capacity. Strategic Management Journal, v. 36, n. 11, p. 1739-1749.

Rauch, A., Wiklund, J., Lumpkin, G. T. \& Frese, M. (2009). Entrepreneurial orientation and business performance: An assessment of past research and suggestions for the future. Entrepreneurship theory and practice, v. 33, n. 3, p. 761-787.

Rossetto, C. R. et al. (2016). Relacionamento entre orientação empreendedora e capacidade absortiva: um estudo com agências bancárias brasileiras. Costa do Sauípe: XL Encontro da Anpad.

Sciascia, S., D’oria, L., Bruni, M. \& Larrañeta, B. (2014). Entrepreneurial Orientation in low-and medium-tech industries: The need for Absorptive Capacity to increase performance. European Management Journal, v. 32, n. 5, p. 761-769.

Sorescu, A. B., Chandy, R. K., Prabhu, J. C. (2003). Sources and financial consequences of radical innovation: Insights from pharmaceuticals. Journal of marketing, v. 67, n. 4, p. 82-102.

Tenconi, C. D. (2015). Desenvolvimento de uma Escala para mensurar a capacidade de absorção em pequenas empresas. Dissertação (Mestrado) - Curso de Administração, Universidade Estadual de Santa Catarina, Florianópolis.

Tian, Amy W.; Soo, C. (2014). Absorptive Capacity and Creative Performance at the Individual Level.

Todorova, G. \& Durisin, B. (2007). Absorptive capacity: Valuing a reconceptualization. Academy of management review, v. 32, n. 3, p. 774-786.

TONIAL, G. (2015). ORIENTAÇÃO EMPREENDEDORA INTERNACIONAL NA INDÚSTRIA VINÍCOLA DO SUL DO BRASIL. 2014. 219 f. Dissertação (Mestrado) - Curso de Administração, Universidade do Vale do Itajai, Biguaçu.

Valentim, L; Lisboa, J; Franco, M. (2015). Knowledge management practices and absorptive capacity in small and medium-sized enterprises: is there really a linkage?. [s. L.]: RE D Management.

Venkatraman, N. (1989). Strategic orientation of business enterprises: The construct, dimensionality, and measurement. Management Science, v. 35, n. 8, p. 
$942-962$.

Zahra, S. \& George, G. (2002). Absorptive Capacity: A Review, Reconceptualization and Extension. Academy of Management Review, v. 27, n. 2, p. 185-203.

Zahra, S. A., Filatotchev, I. \& Wright, M. (2009) How do threshold firms sustain corporate entrepreneurship? The role of boards and absorptive capacity. Journal of business venturing, v. 24 , n. 3, p. 248-260.

\section{Contribuições dos autores na construção} deste artigo:

SBISSA: Concepção da pesquisa, Elaboração da redação do manuscrito, Coleta de dados, Análise e Interpretação dos dados.

ROSSETTO: Revisão Crítica do Manuscrito, Orientação do trabalho.

CARVALHO: Análise Estatística.

ZONATTO: Coleta dos dados, Revisão de normas e formatação. 